\title{
BIOETHICS IN MEDICINE
}

\section{Commentary on the need to obtain consent for vaginal delivery}

\author{
John Anthony, Chantal J M Stewart, Bhavna Patel
}

The arguments in the paper by Dhai et al. ${ }^{1}$ may be summarised as follows:

Since childbirth may take place by vaginal delivery or caesarean section, a choice must be made and consent to vaginal delivery is as necessary as consent for caesarean section. Dhai et al. affirm the patient's right to choose, together with the observation that the safety of vaginal delivery may be limited in the public sector. Rising caesarean section rates and the differences between public and private sector rates are noted. They argue that sound ethical and legal principles should be used in determining mode of delivery. The right to choose is enshrined in the process of informed consent, which requires full disclosure. This includes the possibility that the labour ward may be inadequately staffed. Dhai et al. state that informed consent and respect for patient autonomy are an 'ethical and legal imperative'; furthermore, they argue that failure to obtain consent may be construed to be assault. They also cite the Consumer Protection Act, which stipulates that consumers have a right to the performance of services in a manner and quality that persons may be entitled to expect.

This claim to ethical and legal authority is open to scrutiny; if it goes unchallenged, it will set a new benchmark for obstetric counselling with serious implications for (especially) a public sector overburdened by clinical work and struggling to provide counselling to a diverse population.

\section{Factual considerations}

The morbidity and mortality risks of caesarean delivery are much higher than for normal vaginal delivery. This is due to anaesthetic problems, the operative risk of haemorrhage, and complications such as sepsis and thrombo-embolism. These risks are compounded by the possibility of repeated caesarean section in subsequent pregnancies. The risks of vaginal childbirth have been reduced by fetal monitoring and triaged care, based on recognised risk factors. The absence of adequate monitoring in the labour ward approximates the situation of 'natural' childbirth, and inadequate care is associated with a greater risk of adverse outcome.

The staff numbers and level of training vary between institutions and within the private and public sectors. South African private practice depends largely on obstetricians, who often conduct normal deliveries. The public sector service is based on midwifery, with complicated pregnancies referred to hospitals where patients are managed by

John Anthony is Head of the Maternal and Fetal Medicine Unit at Groote Schuur Hospital, Cape Town, and a member of the Hospital Ethics Committee. Chantal Stewart is the Head of Fetal Medicine at Groote Schuur Hospital. Bhavna Patel is the Chief Operational Officer for Groote Schuur Hospital and a member of the Hospital Ethics Committee. medical officers, registrars and obstetricians. This difference is also reflected in the theatre facilities, with private institutions benefiting from consultant-based anaesthetic management. The level of training influences safe management of both vaginal and caesarean delivery. Public sector anaesthetic deaths are described in the Confidential Enquiries into Maternal Deaths, most of which are avoidable, a circumstance that remains unaccounted for by Dhai et al.

The financial cost of caesarean delivery exceeds that of vaginal birth and access to operative delivery in the public sector is restricted, with close on $50 \%$ of deliveries taking place in facilities without direct access to operating rooms.

The increase in caesarean section rates is in some circumstances based on scientific evidence; the use of electronic fetal monitoring during labour and the risks of dystocia due to operative vaginal delivery and vaginal breech delivery have legitimately increased the rates of operative delivery. However, the disparity between private and public sector caesarean section rates may reflect preference, unrelated to outcome-based evidence. Dhai et al. acknowledge the absence of evidence in favour of or against 'non-medical' caesarean delivery, but justify such interventions by an appeal to an ethical standard of practice. Their assertion that patient autonomy be regarded as an 'ethical and legal imperative' may not be sustainable.

\section{Ethical and legal arguments}

The notion of human dignity emerges in the Enlightenment philosophy of Immanuel Kant. ${ }^{2}$ Kantian theory recognises rationality and the capacity to act from a good will as distinguishing features of humankind. These characteristics set human beings above all other creatures, giving them a dignity 'above all price'. Kant delineates how we ought to treat our fellow human beings: not merely as a means to some other end, but always as an end in themselves. No one should be an instrument to the will of another; everyone should act out of their own sense of free will, encapsulating the idea of autonomy. However, Kantians would acknowledge that autonomous actions are not necessarily morally praiseworthy simply because they are autonomous; the actions of criminals cannot be sustained in any society, no matter how autonomous they may be. A Kantian would not wish to proscribe the actions of anyone, but to see them dealt with within the legal framework of society, which often sets the boundaries of individual liberty. In this context, a statement defending autonomy as an 'ethical and legal imperative' is a contradiction in terms.

The idea of autonomy has nevertheless become deeply entrenched in modern society. The history of the European Enlightenment is one of burgeoning self-realisation at many levels: contemporary technology and its life-transforming iterations rests upon the development of modern science founded upon the power of individual observation and experimentation; modern political power, which has transformed the lives of men and women, is now vested in the hands of individuals to whom governments are held responsible; in moral reasoning, increasingly secular societies trace moral authority to the judgements of individuals who regard themselves as free agents in a global community. It is not surprising that the autonomy of the individual has been celebrated as freedom which some defend at all costs. However, other forms of moral reasoning provide answers without seeing autonomy of the individual as the lynch-pin. 
Some even assert that limitations to individual autonomy are both necessary and justifiable.

Utilitarianism also has a clear focus on the individual, predicating moral judgements not upon the rationality of individuals and their capacity of free and deliberate choice between right and wrong actions, but upon their aggregate happiness. The elusive notion of happiness also encompasses the capacity for suffering. Utilitarians reject the idea that moral value is confined to sentient human beings, perceiving a capacity for suffering also in animals, who are of moral concern to them. ${ }^{3}$ While utilitarians reject restrictions on the liberty of individuals (believing that freedom from interference is partly constitutive of human happiness), they do not invoke autonomy of the individual as the defining characteristic of moral judgement. The attainment of the greatest aggregate happiness may even necessitate overruling the autonomously expressed desires of individuals.

Moral philosophy has more recently re-focused on communitarian philosophy and relational ethics. ${ }^{4}$ Underpinning this is the realisation that while Enlightenment philosophy brought salutary changes to society (technological development, human rights with emancipation of women and the ending of slavery), it also had less acceptable consequences, such as persistent inequalities in wealth and extreme poverty among many communities. Environmental degradation and the industrialisation of war with the development of weapons of mass destruction also speak to our moral intuitions that these changes cannot be right. This has re-awakened the notion that our lives are embedded in the fabric of the community to which we belong and to which we are answerable. Furthermore, as human beings we are instinctively drawn to one another in a precognitive and affective way. ${ }^{5}$ The South African iteration of this philosophy is Ubuntu: a person is a person through other people. We realise our humanity through our inter-relatedness, and to act morally requires good motivation and the exercise of virtue in pursuit of a social role that supports harmonious relationships. The 'ethical and legal imperative' of individual autonomy lies far from the core of this philosophy.

Contemporary bioethical reasoning relies on the principlist approach to ethical reasoning propounded by Beauchamp and Childress. ${ }^{6}$ They enunciated four intermediate-level 'principles' midway between the over-arching principles of deontological and utilitarian ethics and the specific rules derived from them. Their principles gather authority from deductive reasoning and are further refined by inductive argument based upon moral intuitions that fashion our judgements in defined clinical situations. The principles enunciated by Beauchamp and Childress are prima facie principles, true in all circumstances but capable of being overruled when they conflict with one another. The four principles encompass respect for patient autonomy; beneficence (the oldest moral injunction of all); non-maleficence; and respect for the need to attain social justice. Beauchamp and Childress repeatedly point out that patient autonomy has no hegemony among these principles. Where moral deliberation is required, reflective equilibrium may include the need to over-rule autonomy. In doing so, the principle loses none of its moral authority and the person called upon to act in this way may be left with traces of 'moral regret' for what they have been called upon to do.

Ethical argument therefore cannot support what Dhai et al. have referred to as an uncontested 'legal and ethical imperative' to respect patient autonomy. Bioethical deliberation, however, cannot reside in argument alone. Judgements are required and must be made, as demanded by Dhai et al.

Because a choice exists does not inevitably mean that a choice can be made, and using the language of 'rights' cannot finesse this fact. Rights are limited by the interests of others and in South Africa no one can defend even an unqualified right to life, as exemplified by the Soobramoney case in which life-saving dialysis was refused by the High Court. ${ }^{7}$ Where the state lacks capacity to provide support that may be beneficial and desired by an individual it may justifiably be denied. This is true of technological and costly medical care wherever it is practised. The state does not have the capacity to offer caesarean delivery to everyone, and there is no uncontested moral 'right' pertaining to individual autonomy that obliges the state to act in any other way or seek to provide resources that would allow all women to deliver by caesarean section.

Concerning beneficence, it becomes a medical judgement about what is in the best interests of women about to deliver. Based upon the evidence it is not apparent that non-medical caesarean section is beneficial; rather the converse may be true. Furthermore, it seems self-serving to counsel women about the dangers of less than perfect care when no alternative is available. The distress that such counselling occasions may be deemed to be harmful.

Alisdair MacIntyre, a communitarian philosopher, points out the importance of practices in regulating moral behaviour in ancient and modern society: the pursuit of excellence (not merely financial gain), adherence to a body of opinion and the subjugation of practitioners to the judgements of their peers, constitute what he calls a practice. The professional body of doctors who provide clinical care to women during pregnancy adhere to standards of medical practice that are evidence-based and within recognised ethical norms. Thus practitioners practise their profession in pursuit of excellence, under the scrutiny of peer review and not merely in pursuit of self-interest. Within this practice, there is no consistent body of opinion that favours caesarean section over vaginal delivery, and no professional in training would ever be taught thus.

The legal arguments raised by Dhai et al. do not merit discussion. The notion that medical practice be regulated by laws that govern the conduct of business would only have currency if the practice of medicine were seen to be a business with the attendant redirection away from professional ethics to the pursuit of self-interest and profit.

The article by Dhai et al. is speculative and, if adhered to, may decrease litigation. While a decrease in litigation is desirable, it should not be accomplished by shifting the decision-making responsibility and its consequences to individual patients. This seems to be wholly unreasonable. However, decreased litigation founded upon improved medical care would be desirable and meaningful. The pursuit of excellence is precisely what professional practice aims to achieve.

\footnotetext{
. Dhai A, Garner J, Guidozzi Y, Howarth G, Vorster M. Vaginal deliveries - is there a need for documented consent? S Afr Med J 2011;101(1):20-22.

Kant I. The Moral Law: Groundwork of the Metaphysic of Morals. Translated by Paton HJ. London: Routledge Classics, 1991.

Singer P. 2000. Writings on an Ethical Life. London: Fourth Estate, 2000.

4. MacIntyre A. 1985. After Virtue. London: Duckworth Press, 1985.

5. Bergo B. Emmanual Levinas. In: Zalta EN, ed. The Stanford Encyclopaedia of Philosophy. Fall 2008 edition. http://plato.stanford.edu/archives/fall2008/entries/levinas/ (accessed 23 February 2009). Beauchamp TL, Childress JF. Principles of Biomedical Ethics. 5th ed. New York: Oxford University Press, 2001
}

Soobramoney v. Minister of Health (KwaZulu-Natal) 1997 ZACC 17 